\title{
WELD JOINT USING RP MECHANISM
}

\section{Dr. K. PRASANNA LAKSHMI}

Associate Professor, Department of Mechanical Engineering, JNTUH, Telangana, India

KEYWORDS: Weld Bead, Welding Electrode, Welding Parameters, Rack \& Pinion Mechanism, Semi Automated, Welding Joint \& Leg Dimension (Fillet Weld)
\end{abstract}

Received: Oct 05, 2019; Accepted: Oct 26, 2019; Published: Dec 18, 2019; Paper Id.: IJMPERDFEB202013

\section{INTRODUCTION}

Any welding operation has many undesired properties during its ongoing process. Metal Arc Welding is one of the welding process wherein unwanted side effects occur such as undercut, slag inclusions, incomplete fusion, spatter, cracks etc. In order to solve all such problems, a good welding design is required. Welding skill by a workman plays a vital role for obtaining a good weld joint. A small overview on these flaws and their remedies are discussed so as to ensure, all these defects are minimized to some extent in the present operation which is conducted in our workshop by using RP (Rack \& Pinion mechanism), The mechanism is using a welding rod, taken at different angles and the leg dimension of the fillet weld is found out, by which the melting efficiency is calculated. The variation of a set of current with variation of electrode angle is experimented on the formation of weld bead width. Since the RP mechanism is semi automated, the travel speed is maintained constant for any welding operation.

\section{FLAWS AND REMEDIES}

The undercut [1] is an imperfection which forms a groove formation due to overheating when the welder uses either high welding current or fast travel speed. Since the machine is using a regulated speed and current, this problem will not occur. Since inception of oxygen leads to corrosion, electrodes are fluxed. Slag is trapped when two adjacent weld beads are deposited with inadequate overlap and a void is formed and thus entrapped slag is not melted. A smooth weld bead profile will remove the slag inclusions. This is achieved by a semi automated machine. Since this machine operation will give a smooth weld bead profile, incomplete penetration/fusion occurs due to poor adhesion 
of weld bead to the base metal which does not start at the root of the weld groove. Since a regulated high welding current with appropriate voltage is used, this defect is minimized. While molten metal and filler material forms a molten pool, very high temperatures and volatility occurs in the welding zone. Due to arc forces, gas [pressures and magnetic forces, molten metal is liable to splash and these globules come in contact with the cold parent material and solidify and get stuck on the surface. This is called spatter. Lowering the amperage of the welding setup can reduce the spatter, which can be achieved in the present machine being used. If the welding arc is properly terminated and shrinkage is not restricted, cracking can be avoided. In the present set up, termination can be done properly so that the weld pool is not left unfilled at the ends and crack does not form there. But shrinkage restriction can be regulated only by proper usage of the materials, provided the temperatures are regulated properly [1]. The experimental setup ensures that the automation reduces the lacunae occurred due to manual handling of the electrode and the flow of the current is in controlled manner. A proper alignment of the electrode and electrode angle makes the weld with minimum defect.

\section{INFLUENCE OF WELDING PARAMETERS}

There are many such relations in welding parameters where it is either directly proportional or inversely proportional to various variables. Higher current results in deeper penetration, leading to waste of electrodes and undercutting. Changes in the arc length (controlled by the welder) will further change the amperage. Longer arc lengths reduce amperage. Lower Arc voltage results in narrow bead and higher travel speed leads to undercut. Therefore, an optimum value of both is taken in order to avoid narrow bead and undercutting [4].

\section{Amperage}

How to determine the correct amperage [2] for a certain electrode will depend on the size and classification of the electrode. Even the type of joint and welding position must be considered. The process requires sufficient electric current to melt the both the electrode and a proper amount of base metal. The higher the current, the deeper the penetration. Using higher amperage may cause problems such as excessive spatter, electrode overheating and cracking.

\section{Arc Voltage}

The voltage of the arc [3] varies within narrower limits than the current of the welding. This influences the length and form of the bead. Low voltages make the bead wider and flatter. Extremely high voltage of the arc should be avoided as it may cause cracking. The low voltage of the arc produces a stiffer arc for better penetration. If the voltage is too low, it will result in a very narrow bead.

\section{Travel Speed}

The velocity moving by the electrode along the joint has a direct impact on the form of the bead, fusion thickness, aesthetic appearance and heat input into the base metal. Faster travel speeds [4] produce less penetrating beads. This can be a benefit for sheet metal welding where it requires small beads and low penetration. Travel speed also affects the input of heat, which in turn affects the weld metal's metallurgical structure. The heat-affected area will also increase in size and decreases the cooling rate. However, when speeds are too high, there is a tendency towards undercutting and porosity, as the weld freezes faster.

\section{Electrode Angle}

The electrode angle [5] plays a vital role at the point of impingement and is responsible for the weld bead profile. The electrode angle with bigger size will make high penetration. The electrode angle with lower size will make the welding incomplete due to 
lack of proper penetration or fusion. However, for different types of welding positions, different electrode angles may be calculated. Welding can be carried out with the electrode wire leading, trailing and normal to the plate surface and the effects on weld shape, penetration and undercut. Welding with the electrode wire pointing forward, i.e. leading by $10^{\circ}$, is standard for most applications in order to obtain the best combination of bead size, penetration and undercut resistance.

There are many other factors which influence the welding characteristics, but investigation is done only on the variation of the above factors mentioned.

\section{DESIGN OF SEMI AUTOMATED MACHINE}

The model is designed for semi-automated operations that can result in reliability, better welding, and cost-effectiveness that restrict human intervention to loading and unloading, and device installation and off. The speed is varied and various welds are obtained while current flows in the electrodes at a particular voltage. For regulating the voltage and amperage, regulator power supply is used as shown in Figure 1.

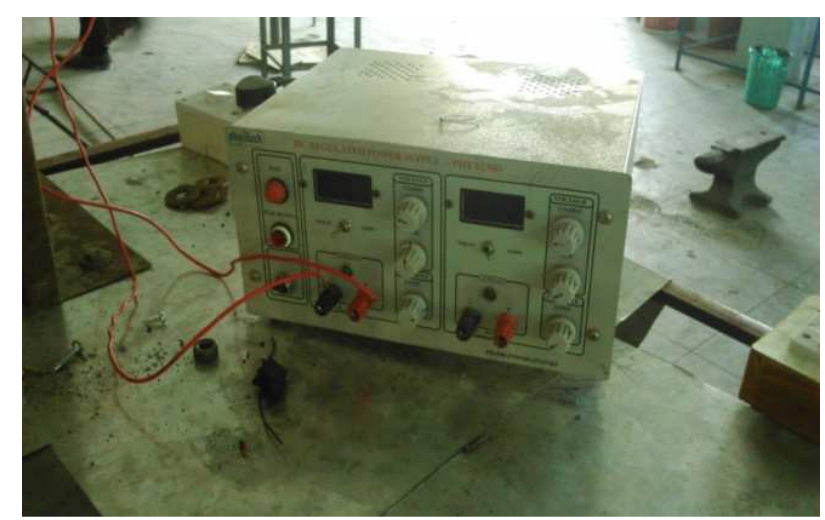

Figure 1: Regulated Power Supply Device.

The speed of the electrode is decided by the movement of welding rod which is attached to the pinion. This pinion is attached to the motor. The speed extent (fast or slow) in which rod moves is dependent on the rpm of the motor. Since rpm is very less, high torque motor is required. The pinion is set up in such a way that the welding rod can be held at a desired angle at the pinion, and, as the pinion moves on the rack as shown in Figure 2, the electrode will also move with the same speed accordingly.

The high torque motor and the pinion is set up in such a way, it can weigh the load of the welding rod. The pinion shaft is coupled to an electric motor for its drive. The motor is given power supply through RPS. The rotary motion of pinion which is fetched by the motor at desired rpm is converted to linear motion on the rack. The welding rod holder is attached to the static portion of the pinion which will give a linear motion to the welding rod. The rack is placed on an adjustable table. This is used for the purpose of getting different linear velocities of the rack by regulating the power supply through RPS.

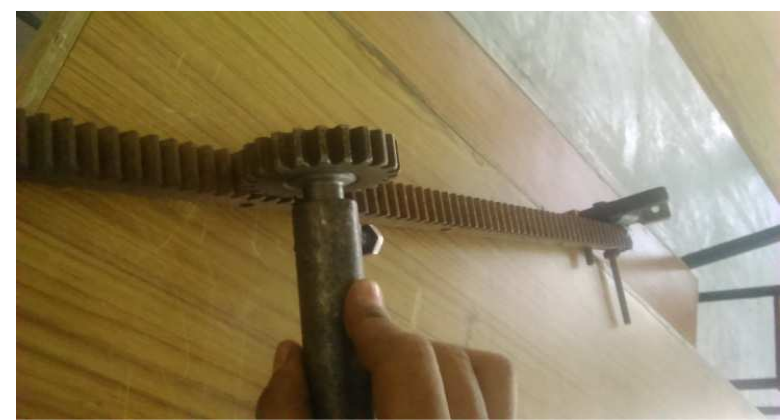

Figure 2: Rack \& Pinion (RP) Attached to Motor. 
A varied RPM of the motor shaft can be achieved thus getting different linear velocities. The supporting plates have been provided with two supporting bars, where one is fixed at its position and the other one is provided with long slot where it can slide from top to bottom fixing at various positions. The position of the second supporting bar decides the angle of the rack.

\section{RP MECHANISM}

This set up is semi automated, as the loading of the welding rod, setting the voltage and current, setting the welding rod at a desired position at an angle according to the placement of the plates to be welded, adjusting the table in the form of frame, all such operations are to be done manually. Thus, for the different combinations of angle of the welding rod and RPM of the motor shaft, we can achieve the wide range of weld velocities and feed rates. As we are changing the angle of the welding rod, there is requirement of adjustable table for maintaining the required distance between the electrode and the weldment.

Although motor gives $10 \mathrm{RPM}$ at $12 \mathrm{~V}$, but motor runs smoothly from $4 \mathrm{~V}$ to $12 \mathrm{~V}$ and gives wide range of RPM, and torque. Tables 1 depicts fairly good idea of the motor's performance in terms of RPM and no load current as a function of voltage and stall torque, stall current as a function of voltage. With the adjusting table, we can vary the work piece height from the ground level so as to compensate the changes in the angle of rack [6] which makes the changes in distance of electrode from base level. This has been provided for supporting the whole rack and pinion and motor set up. There are two horizontal supports provided on the plates, one is fixed at its point and the other can be moved vertically up and down for achieving different angles of the rack, as per the requirement. The mechanism is shown in Figure 3. In this Figure, the Rack changes its position with respect to horizontal, so that one need not change the electrode. The holder holding the electrode which is attached to the frame has to bear the weight of the electrode. The electrode is likely to slip at various changes of the electrode angle. Therefore, the electrode is fixed to the frame and attached to the rack. Instead of changing the angle of the electrode, the rack will change its position such that the electrode angle position is satisfied. For the rack to change its position it is placed on an adjustable table, wherein the one end is fixed and the other end is movable. Depending upon the position an electrode vary its angle, the movable end of the rack is moved. The electrode is positioned across the plates to be welded at an appropriate distance. And once the electrode angle is fixed, then the motor gives the moment to the electrode holder, which is attached to the pinion, moves on the rack and the welding operation takes place. The movement of the welding rod is according to the RPM of the motor. Very low RPM, high torque motor is used to carry the operations. The movement of the electrode is completely automatic till the end of the welding. But, since other operations on this welding set up requires human intervention, it is named as semi automatic welding set up. The welding rod is flux coated so as to provide the shielding to the welding operation. The voltage and the current supplied to the welding rod are properly regulated using a power regulated supply device. The arc produced in the electrode rod will join the plates to be welded. 




Figure 3: Rack \& Pinion Mechanism for Movement of Electrode.

\section{PERFORMANCE CHARACTERISTICS OF WELDING PARAMETERS ON MS PLATE}

Performance is calculated using the Selection of base material and filler material: Base metal: Mild steel plate, Filler material/Electrode type: E6013 (Rutile potassium based flux coated mild steel electrode), Type of current: electrode positive (DCEP), diameter of electrode $-3.5 \mathrm{~mm}$

The welding joint is performed on the plates of thickness $4.98 \mathrm{~mm}$ and butt joint is formed, as shown in Figure 4 .

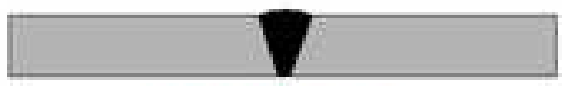

\section{Butt Joint}

Figure 4: Butt Joint.

The following table shows the leg dimension of the Butt Joint, electrode angle being $45^{\circ}$, as shown below and the graphical representation of the same is shown in Figure 5.

Table 1: Welding Electrode Angle $4^{\circ}$, Butt Joint

\begin{tabular}{|c|c|c|c|c|c|c|}
\hline S. No. & Voltage & Current & RPM & Time & $\begin{array}{c}\text { Flat Distance } \\
\text { Leg (mm) }\end{array}$ & $\begin{array}{c}\text { Yield } \\
\text { Strength }\end{array}$ \\
\hline 1 & 5 & 20 & 5 & 18 & 8.0 & 61.15 \\
\hline 2 & 6 & 30 & 6 & 15 & 8.2 & 61.15 \\
\hline 3 & 7 & 40 & 7 & 12 & 8.34 & 61.15 \\
\hline 4 & 8 & 50 & 8 & 11 & 8.76 & 62 \\
\hline 5 & 9 & 80 & 9 & 10 & 8.85 & 65.4 \\
\hline 6 & 10 & 100 & 10 & 10 & 8.9 & 67.2 \\
\hline
\end{tabular}

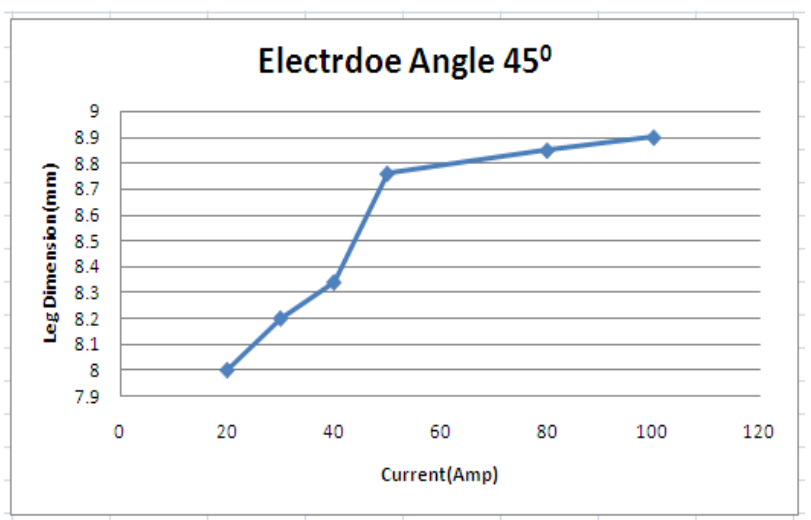

Figure 5: Graph Shows the Variation of Current vs Leg Dimension for an Electrode Angle of $\mathbf{4 5}^{\circ}$. 
The welding joint is performed on the plates of thickness $4.98 \mathrm{~mm}$ and a $\mathrm{T}$ joint is formed as shown in Figure 6.

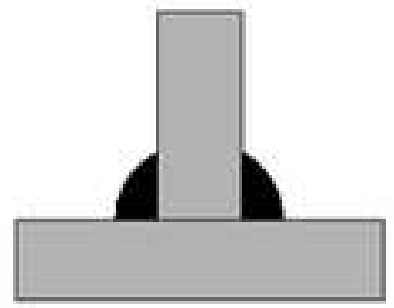

Tee Joint

Figure 6: The T Joint, Welding Performed on Both Sides.

The following table shows the leg dimension [7] of the $\mathrm{T}$ joint. Both horizontal and vertical leg dimensions were measured for an electrode angle of $30^{\circ}$. The graphical representation of Current with Horizontal and vertical leg dimension is shown in Figure 7.

Table 2: For Welding Angle of $30^{\circ}$, T Joint on Both Sides, Tensile Strength $\mathbf{- 5 2 . 3 ~ N / \mathbf { m m } ^ { 2 }}$

\begin{tabular}{|c|c|c|c|c|c|c|}
\hline \multirow{2}{*}{ S. No. } & \multirow{2}{*}{ Voltage } & \multirow{2}{*}{ Current } & \multirow{2}{*}{ RPM } & \multirow{2}{*}{ Time } & \multicolumn{2}{|c|}{ Leg Dimension } \\
\cline { 5 - 7 } & & & & & Horizontal & Vertical \\
\hline 1 & 5 & 20 & 5 & 18 & 1.96 & 2.00 \\
\hline 2 & 6 & 30 & 6 & 15 & 1.99 & 2.02 \\
\hline 3 & 7 & 40 & 7 & 12 & 2.13 & 2.07 \\
\hline 4 & 8 & 50 & 8 & 11 & 2.22 & 2.13 \\
\hline 5 & 9 & 80 & 9 & 10 & 2.32 & 2.19 \\
\hline 6 & 10 & 100 & 10 & 10 & 2.45 & 2.25 \\
\hline
\end{tabular}

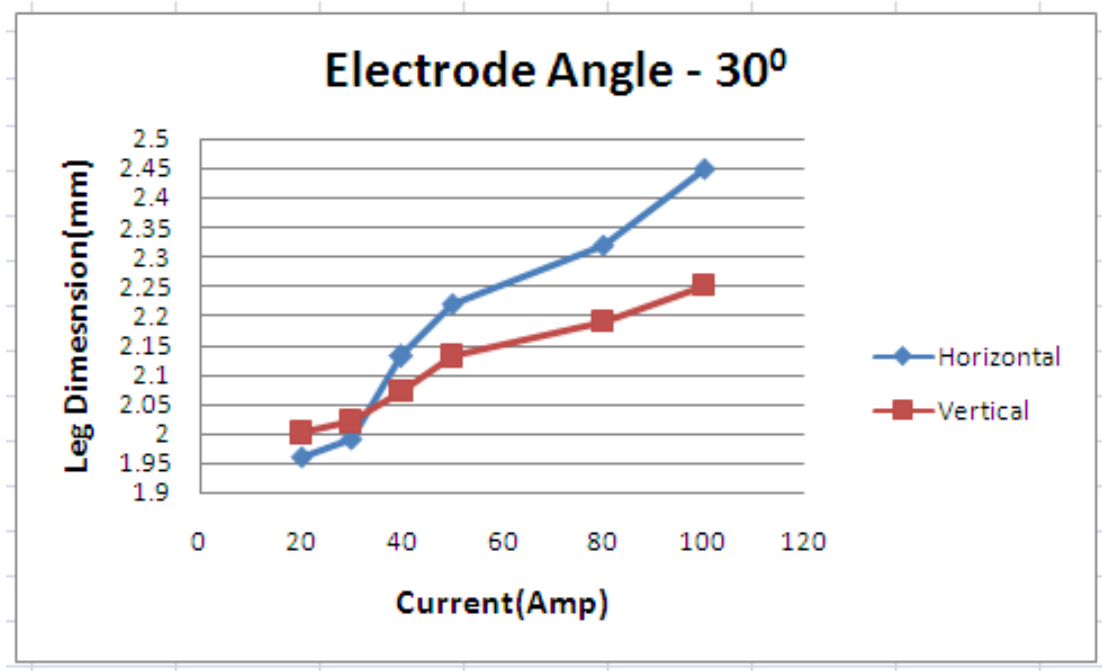

Figure 7: Graphical Representation Horizontal \& Vertical Leg Dimensions, Welding Rod Angle 30 ${ }^{\circ}$.

The table shows the variation of voltage, current, rpm and time versus the leg dimensions in both horizontal and vertical faces of the $\mathrm{T}$ joint. The electrode angle plays a vital role, and the experiment is focused on the how the leg dimensions vary with respect to electrode angle and thus produces impact on tensile strength. The following table shows the leg dimension of the $\mathrm{T}$ joint. Both horizontal and vertical leg dimensions were measured for an electrode angle of $45^{\circ}$. 
Table 3: For Welding Angle of $\mathbf{4 5}^{\circ}$, T Joint on Both Sides, Tensile Strength $\mathbf{- 4 8 . 9}$ N/mm

\begin{tabular}{|c|c|c|c|c|c|c|}
\hline \multirow{2}{*}{ S. No. } & \multirow{2}{*}{ Voltage } & \multirow{2}{*}{ Current } & \multirow{2}{*}{ RPM } & \multirow{2}{*}{ Time } & \multicolumn{2}{|c|}{ Leg Dimension } \\
\cline { 5 - 7 } & & & & & Horizontal & Vertical \\
\hline 1 & 5 & 20 & 5 & 18 & 1.98 & 1.98 \\
\hline 2 & 6 & 30 & 6 & 15 & 2.01 & 2.01 \\
\hline 3 & 7 & 40 & 7 & 12 & 2.23 & 2.23 \\
\hline 4 & 8 & 50 & 8 & 11 & 2.40 & 2.40 \\
\hline 5 & 9 & 80 & 9 & 10 & 2.48 & 2.48 \\
\hline 6 & 10 & 100 & 10 & 10 & 2.54 & 2.54 \\
\hline
\end{tabular}

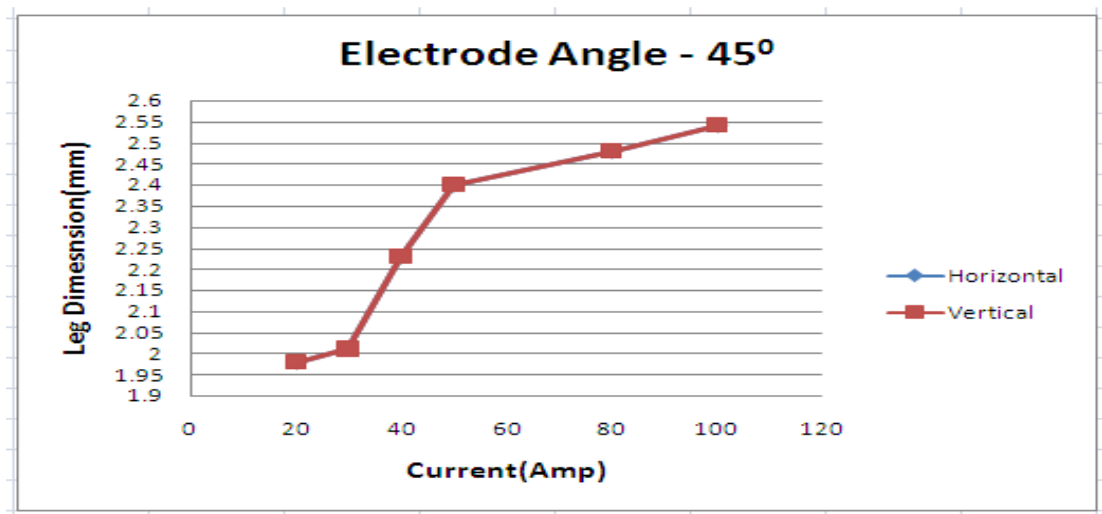

Figure 8: Graphical Representation Horizontal \& Vertical Leg Dimensions, Welding Rod Angle $\mathbf{4 5}^{\circ}$.

The graphical representation of the Leg dimensions with Current at an electrode angle of $45^{0}$ is shown in Figure 8.

The following table shows the leg dimension of the $\mathrm{T}$ joint. Both horizontal and vertical leg dimensions were measured for an electrode angle of $60^{\circ}$.

Table 4: For Welding Angle of $60^{\circ}$, T Joint on both Sides, Tensile Strength $\mathbf{- 4 6 . 5 ~ N / m ^ { 2 }}$

\begin{tabular}{|c|c|c|c|c|c|c|}
\hline \multirow{2}{*}{ S. No. } & \multirow{2}{*}{ Voltage } & \multirow{2}{*}{ Current } & \multirow{2}{*}{ RPM } & \multirow{2}{*}{ Time } & \multicolumn{2}{|c|}{ Leg Dimension } \\
\cline { 5 - 7 } & & & & & Horizontal & Vertical \\
\hline 1 & 5 & 20 & 5 & 18 & 2.10 & 1.96 \\
\hline 2 & 6 & 30 & 6 & 15 & 2.18 & 1.94 \\
\hline 3 & 7 & 40 & 7 & 12 & 2.25 & 1.92 \\
\hline 4 & 8 & 50 & 8 & 11 & 2.32 & 1.90 \\
\hline 5 & 9 & 80 & 9 & 10 & 2.40 & 1.88 \\
\hline 6 & 10 & 100 & 10 & 10 & 2.49 & 1.86 \\
\hline
\end{tabular}

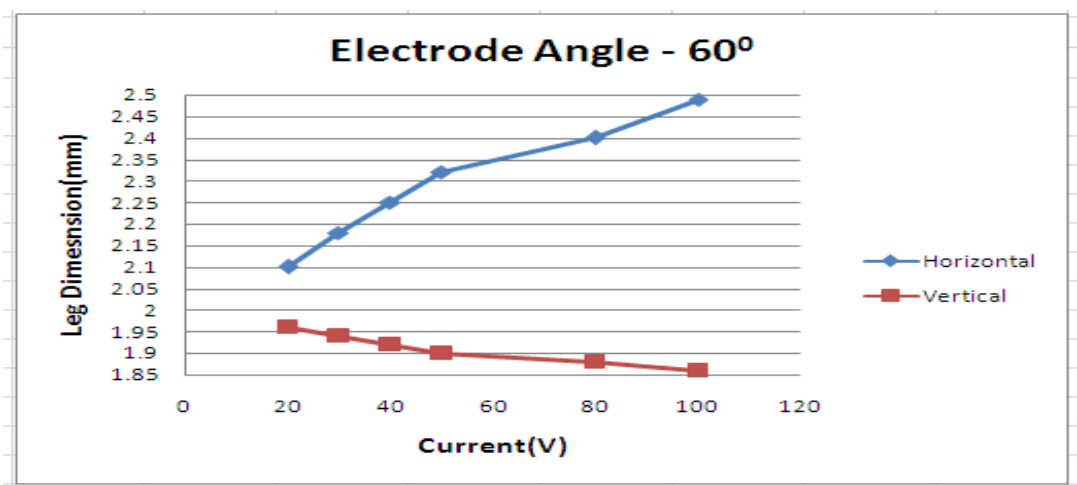

Figure 9: Graphical Representation Horizontal \& Vertical Leg Dimensions, Welding Rod Angle 60. 
How the current varies with horizontal and vertical leg dimension is shown in Figure 9. Increase in voltage and current increases the heat input, which creates a space for defect, inferring reduction in mechanical properties. But in our experiment, as there is no significant increase in voltage, there is no significant change in yield strength.

\section{Effect of Electrode Angle on Weld Bead Width}

The RP mechanism allows the electrode to move at various angles. Using this method, it is discovered for the same set of current variations, how the weld bead varies and what is the effect of weld bead on weld performance. Using this mechanism, some of the results can be found out for the weld bead width for constant amperage, as shown in Figures from Figure 10 to Figure 12. Figure 13 shows the variation of weld bead width for variation of electrode angles for constant amperage. The tabular column and the figures during experimentation show various parameters with respect to constant current. Subsequently, the graph is drawn in the Figure 14 to illustrate the effects of electrode angle and current on weld bead. The electrode angle has an impact on the weld bead, which in turn infers the depth of penetration. So, electrode angle indirectly affects the quality of the weld. In the present experiment, only three (3) electrode angles and three (3) amperages are considered.

The following figure shows how the weld bead looks for a constant set of current.

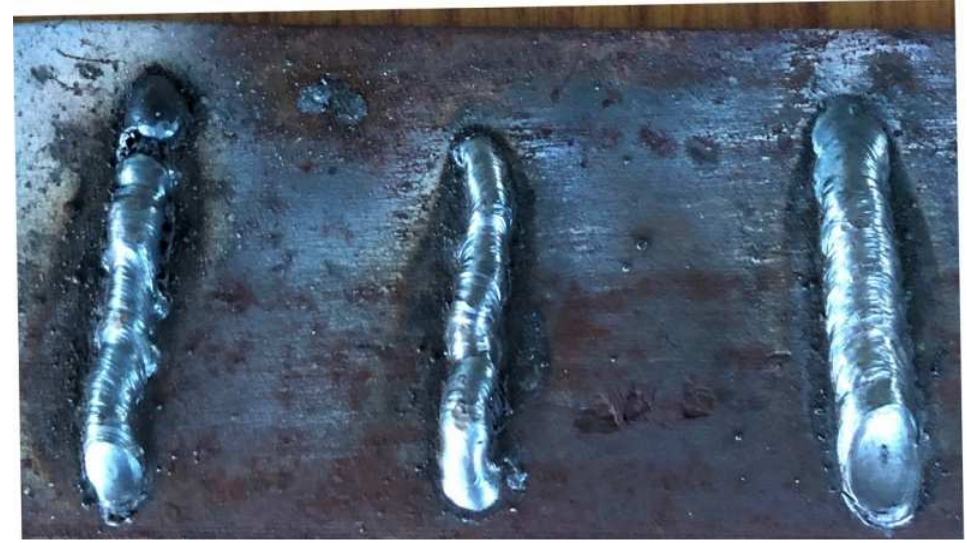

Figure 10: The Variation of Weld Bead Width for Electrode Angle of $30^{\circ}, 45^{\circ}, \& 60^{\circ}$ for a Current of 20 Amps

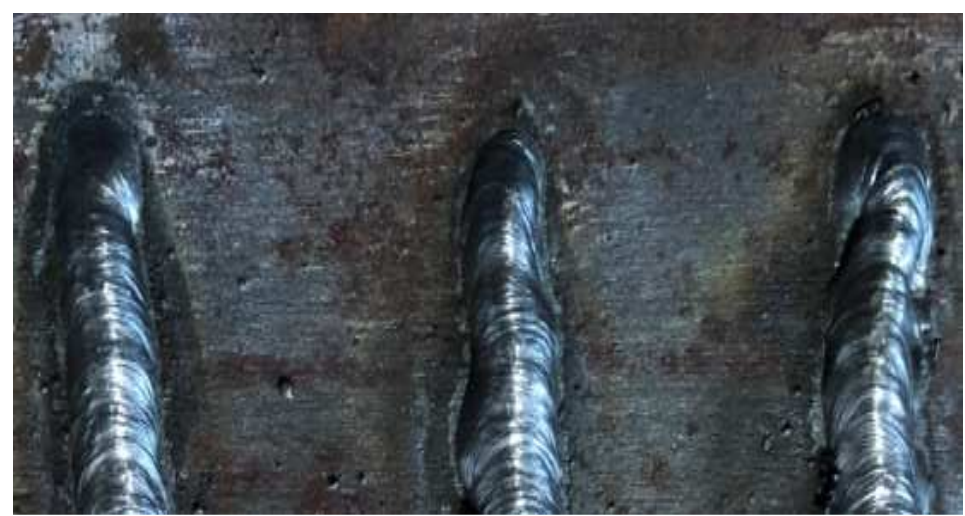

Figure 11: The Variation of Weld Bead Width for Electrode Angle of $30^{\circ}, 45^{\circ}, \& 60^{\circ}$ for a Current of 60 Amps 


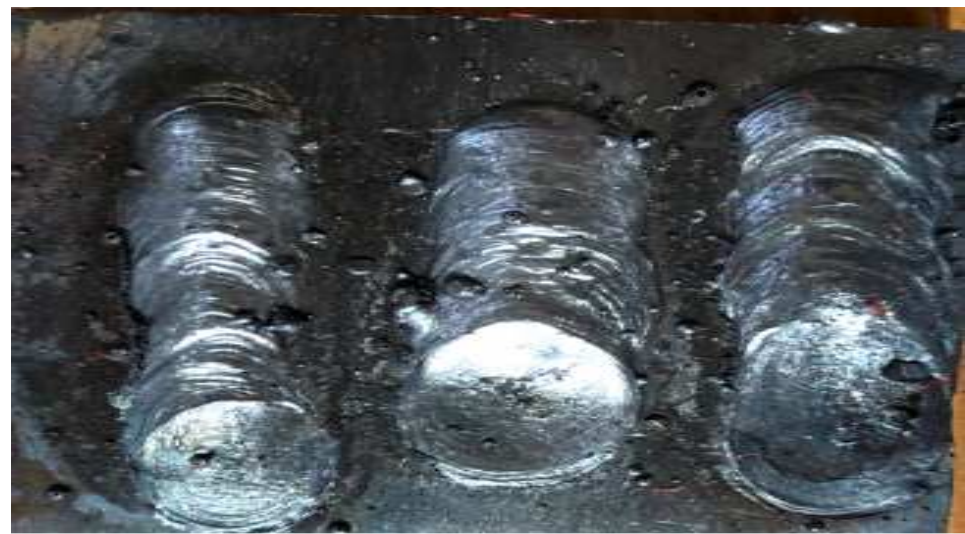

Figure 12: The Variation of Weld Bead Width for Electrode Angle of $30^{\circ}, 4^{\circ}, \& 60^{\circ}$ for a Current of 100 Amps

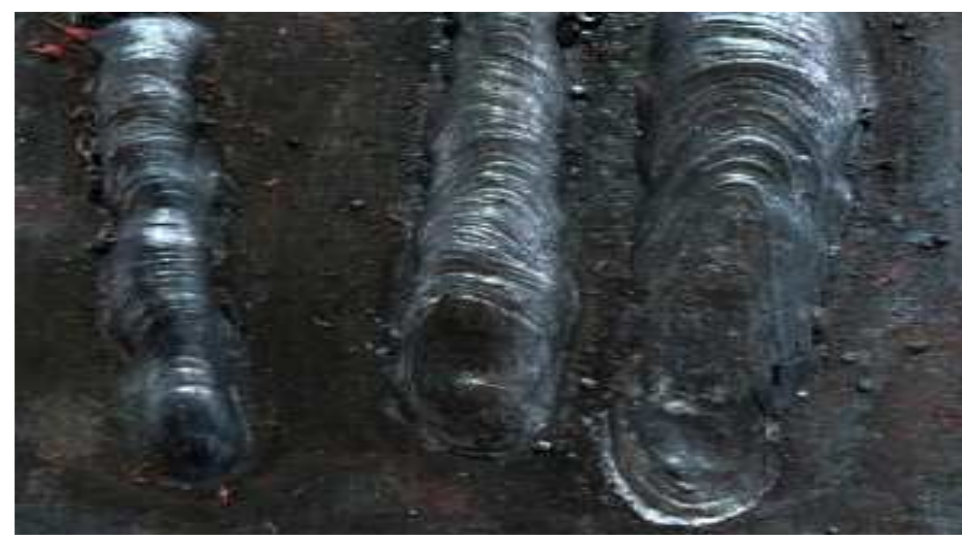

Figure 13: The Variation of Weld Bead Width for 10, 50, and 100 Amps Current for an Electrode Angle of $30^{\circ}$

Table 5: Effect of Amperage AND Electrode Angle (EA) on the Weld Bead Width

\begin{tabular}{|c|c|c|c|}
\hline $\begin{array}{c}\text { Amperage (Amps)/ } \\
\text { Electrode Angle }\end{array}$ & $\mathbf{3 0}^{\mathbf{0}}$ & $\mathbf{4 5}^{\mathbf{0}}$ & $\mathbf{6 0}^{\mathbf{0}}$ \\
\hline 20 & 3.5 & 3.54 & 3.8 \\
\hline 60 & 4.2 & 4.33 & 4.54 \\
\hline 100 & 4.8 & 5.0 & 5.2 \\
\hline
\end{tabular}

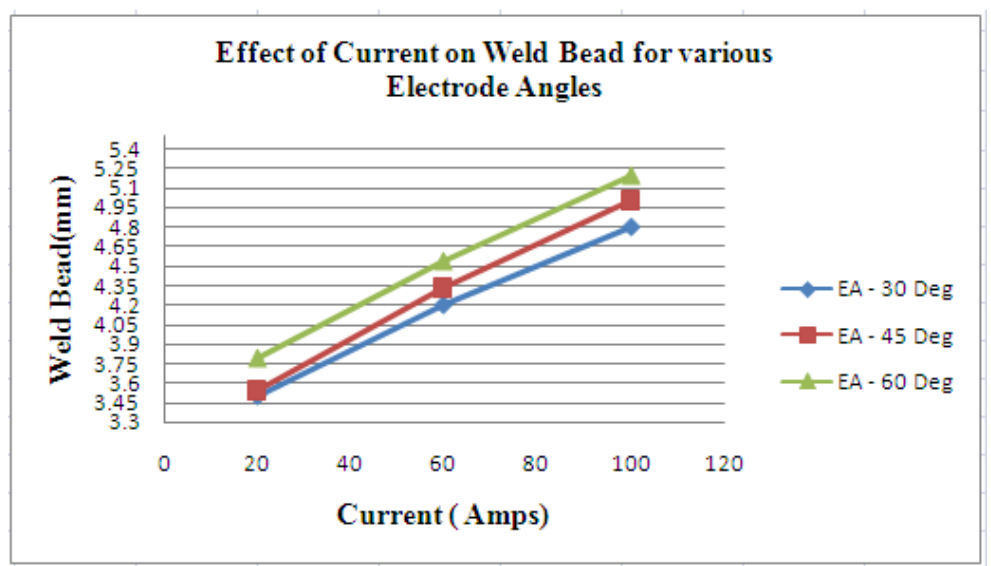

Figure 14: The Figure Shows the Influence of Current on Weld Bead for Various Electrode Angles 


\section{CALCULATIONS}

The net heat supplied at the weld joint for welding speed of $\mathrm{v}=2 \mathrm{~mm} / \mathrm{sec}$,

$\mathrm{H}_{\text {req }}-10 \mathrm{~J} / \mathrm{mm}^{3}, \mathrm{f}$ (heat transfer -0.98

Melting Efficiency [8] can be calculated as shown below:

$\mathrm{H}_{\text {net }}=\frac{f V I}{v} \mathrm{~J} / \mathrm{s}$,

$4^{\text {th }}$ Specimen for electrode angle of $45^{0}$

$\mathrm{H}_{\text {net }}-\frac{0.98 \times 8 \times 50}{2}=196 \mathrm{~J} / \mathrm{mm}$

Heat required for melting $-4 \times 2 \times 10=80 \mathrm{~J} / \mathrm{mm}$ for $1 \mathrm{sec}$,

Melting efficiency - $\frac{\text { Heat } \quad \text { Re quired }}{\text { Heat } \quad \text { Supplied }}=\frac{80}{196}=40.81 \%$

Table 6

\begin{tabular}{|c|c|c|}
\hline Electrode Angle(In degrees) & C/S Area of the Joint( $\mathbf{m m}^{\mathbf{2}}$ ) & Melting Efficiency \\
\hline 30 & 4.2 & 42.85 \\
\hline 45 & 4 & 40.81 \\
\hline 60 & 4.5 & 45.91 \\
\hline
\end{tabular}

$6^{\text {th }}$ Specimen for electrode angle of $45^{0}$

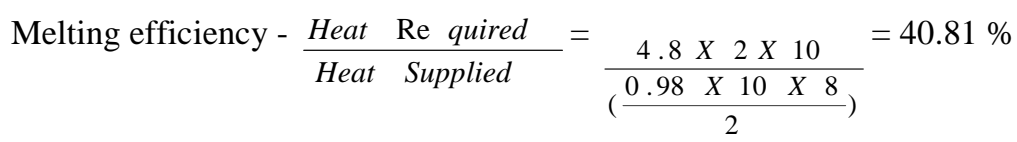

Table 7

\begin{tabular}{|c|c|c|}
\hline Electrode Angle( In degrees) & C/S Area of the Joint $\left(\mathbf{m m}^{\mathbf{2}}\right)$ & Melting Efficiency \\
\hline 30 & 5.1 & 42.85 \\
\hline 45 & 4.8 & 40.81 \\
\hline 60 & 5.3 & 45.91 \\
\hline
\end{tabular}

\section{RESULTS \& CONCLUSIONS}

This paper that is has dealt with an investigation on the effect of welding parameters on the weld bead and leg dimensions. Elongation \& Brinell hardness Number were also found out for various specimens. The experimental values found were, Yield strength - 61.15 MPa, \% Elongation - 3.1\%, Brinell Hardness Number - 80 BHN on Mild Steel with thickness of $4.89 \mathrm{~mm}$. The graphical representation shows the weld leg dimensions, both in horizontal and vertical faces of a $\mathrm{T}$ joint, resulting for the welding angle of $45^{\circ}$ to have equal flow of molten metal and thereby depth of penetration is uniform. Tensile strength is higher for welding angle of $30^{\circ}$ as compared to the other two positions. Tensile strength is least for welding angle of $60^{\circ}$ as compared to the other two positions. The Figure 15 shows the UTM testing machine finding the tensile strength of the T Joint.

The calculations were done randomly for $4^{\text {th }}$ and $6^{\text {th }}$ specimen. It is concluded that melting efficiency is more for electrode angles of $30^{\circ} \& 60^{\circ}$ as compared to $45^{\circ}$. But tensile strength of $45^{\circ}$ electrode angles is more than $30^{\circ}$ and $60^{\circ}$ 
electrode angle. Therefore, an optimum value has to be calculated for getting a high melting efficiency and high tensile strength.

The weld bead width is found out for various combinations. The result obtained infers that the increase in current amperage increases the weld bead width. It also shows that the increase in electrode angle tends to increase the weld bead width. Figure 13 concludes that increase in amperage for the same electrode angle tends to increase the weld bead width.

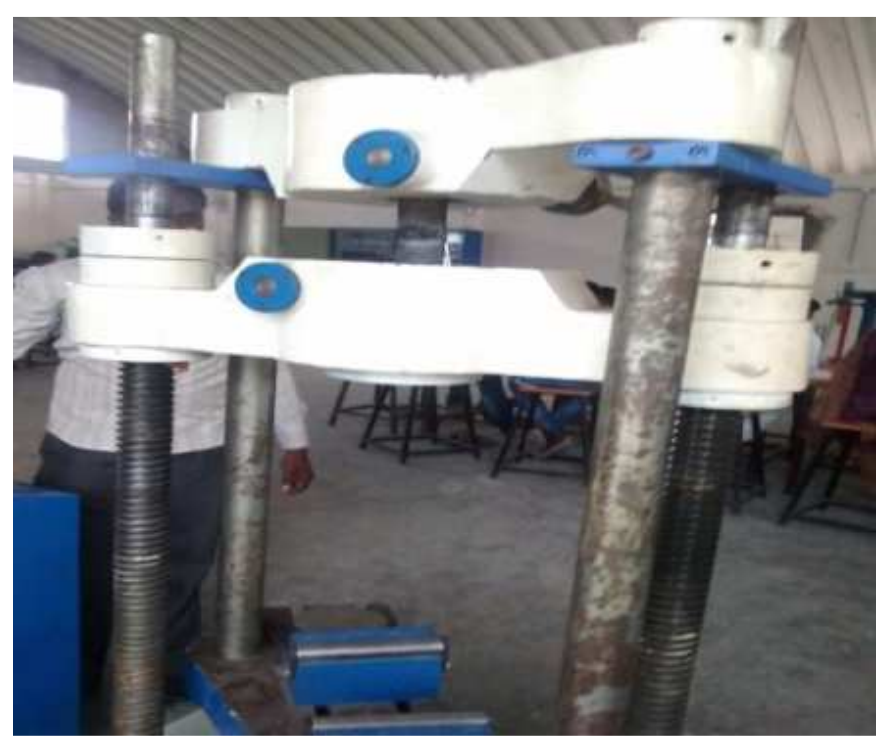

Figure 15: Tensile Test Conducted on UTM of a T Joint Specimen

Further scope of the study includes the variation of travel speed electrode diameter, voltage, current, arc length, feed, welding process with different base metals.

\section{REFERENCES}

1. Joseph Achebo \& Sule Salisu. (2015). Reduction of Undercuts in Fillet Welded Joints Using Taguchi Optimization Method, Journal of Minerals and Materials Characterization and Engineering.(03-03), pp 171-179.

2. HR Ghazvinlo0, A Honarbakhsh, Rouf \& N Shadfar. (2010). Effect of arc voltage, welding current and welding speed on fatigue life, impact energy, and bead penetration of AA6061 joints produced by robotic MIG welding, Indian Journal of Science \& Technology, Vol 3 (Issue 2).

3. Kumar, A. P., \& Krishna, C. S. R. Sensitivity Analysis Of Tig Welding Parameters For Astm-500 Grade B Weldments.

4. $\quad$ R Sakthivel, $P$ Venkadeshwaran, $R$ Sridevi, R Ahamed Meeran \& K Chandrasekharan. Effect of Welding Current, Arc Voltage and Gas Flow Rate on Depth of Penetration during MIG Welding of AA2014 Plate. International Journal of Advance Research in Technology, Engineering And Science. Vol 2, Issue 2. April 2015.

5. Bodade, P. R., Jogi, N., Gorde, M., Paropte, R., \& Waghchore, R. Use Of Internal Threads Of Different Pitches To Enhance Heat Transfer In A Circular Channel.

6. H K Arya. [2012]. Effect of current, voltage and travel speed on micro hardness of SAW welded mild steel plate. National Conference on advancement in Mechanical Engineering and Energy Environment.

7. HR Ghazvinlo0, A Honarbakhsh, Rouf \& N Shadfar. (2010). Effect of electrode to work angle, filler diameter and shielding gas type on weld geometry of HQ130 steel joints produced by robotic GMAW. 
8. Yunus Mohammed, \& Alsoufi M. S.(2015). A statistical analysis of joint strength of dissimilar aluminium alloys formed by friction stir welding using taguchi design approach, anova for the optimization of process parameters. IMPACT: International Journal of Research in Engineering \& Technology (IMPACT: IJRET), 3(7), 63-70.

9. Keerthi Vaasan SV, Faizal Khan A, Gowthaman N \& Kavin L. (2018). Design of Reciprocating Rack \& Pinion mechanism Dual Working Mechanism. International Journal of Science \& Engineering, Vol 1 (1).

10. John Hicks. [1999]. Calculating Weld Size. Welded Joint Design (Third Edition).

11. Rathod, C. H. A. N. D. A. R., \& Reddy, G. K. (2016). Experimental investigation of angular distortion and transverse shrinkage in $\mathrm{CO} 2$ arc welding process. International Journal of Mechanical Engineering, 5(4), 21-28.

12. AW Orlowicz \& A Trytek. (2003). A study of Arc and Melting efficiency in GTAW Process. Archiwum Odlewnictwa, Vol 3, Book 8, pp 131-140.

\section{AUTHORS PROFILE}

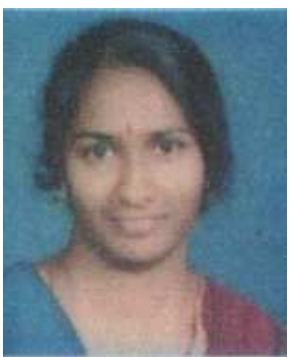

Dr. K Prasanna Lakshmi, Associate Professor in Department of Mechanical Engineering is currently working with JNTUH College of Engineering, Manthani. She has completed B.Tech (Mechanical Engineering) from NBKRIST in 1997, SVU, M.Tech (Production Engineering) from SVU in 2000, PhD (Motion Planning of Multiple Robots) from JNTU Anantapur in 2011. Publications: Two (2) National Journals, Three (3) National Conference, Eleven (11) International Journals, Six (6) International Conferences. She was awarded for best paper presentation in Nov 2009 in Science Congress. She is presently guiding Six (6) PhD scholars. She is currently member of MISTE, AMIE, MIIPE. She is currently working as Acting Advisor for IEISC (Institute of Engineers India, Students Chapter, Ramagundam Local Centre). She also holds the role of Joint Secretary for Institute of Engineers, India, RLC. 